\title{
Termal ısınma-soğuma döngülerine maruz bırakılan mermerlerde soğuma şeklinin fiziksel ve mekanik özellikler üzerindeki etkisinin araştırılması
}

\author{
Investigation of the effect of cooling type on physical and mechanical properties of marbles \\ exposed to thermal heating-cooling cycles
}

\author{
Engin ÖZDEMİR*1,a \\ ${ }^{I}$ İnönü Üniversitesi, Mühendislik Fakültesi, Maden Mühendisliği Bölümü, 44280, Malatya
}

• Geliş tarihi / Received: 11.05.2021 • • Düzeltilerek geliş tarihi / Received in revised form: 07.09.2021 • Kabul tarihi / Accepted: 24.09.2021

\begin{abstract}
$\ddot{O} z$
Doğal taşların kullanım alanları belirlenirken yalnız fiziksel ve mekanik özelliklerine değil aynı zamanda maruz kalacağı ortamın da dikkate alınması gerekmektedir. Özellikle, ani hava değişimi yaşanan bölgelerde doğal taşların parçalanması ve ayrışma mekanizmalarını anlamak için termal değişikliklerin etkisinin araştııılması gerekmektedir. Bu çalışmada, ani ve yavaş gelişen 1sı değişimlerinin Elazı ̆ Vişne ve Petrol Yeşili mermerlerine ait fiziko-mekanik özelliklerinde meydana gelen değişimler araştırılmıştır. Öncelikle üç test grubu oluşturulmuş ve bunlardan birincisi doğal, ikincisi havada yavaş soğuma sonuncusuna ise ani soğuma çevrimlerine tabi bırakılmıştır. Bu amaçla, termal döngülere (ani ve yavaş soğuma) maruz kalan mermerlerin ağıllık kaybı, ağırlıkça-hacimce su emme ve nokta yükleme dayanım değerlerinde meydana gelen değişimler belirlendi. Elde edilen bulgular değerlendirildiğinde, her iki mermer için, ani soğumanın yavaş soğumaya nazaran daha fazla tahrip ettiği tespit edildi. Fakat termal döngüler sonrasında Hazar petrol yeşili mermerindeki dayanım kaybı Elazığ vişneye nazaran daha olduğu tespit edildi. Benzer olarak, Hazar petrol yeşili mermerindeki porozite ve su emme artışı Elazığ vişne mermerinden daha fazladır.
\end{abstract}

Anahtar kelimeler: Elazığ vişne mermeri, Hazar petrol yeşili, Nokta yükleme dayanımı, Termal döngü

\begin{abstract}
While determining the usage areas of natural stones, not only physical-mechanical properties but also environment to which it will be exposed should be taken into account. Especially, to understand the mechanisms of rock breakdown and weathering in regions with sudden air changes, the effect of thermal changes on natural stones should be investigated. In this study, physico-mechanical changes of sudden and slow temperature changes of Elazig Rosso Levanto and Hazar Verde Antico marbles were investigated. First of all, three test groups were formed, the first of which was natural, the second was slow cooling in air and the last was sudden cooling cycles. For this purpose, changes in weight loss, weightvolume water absorption and point load strength values of marbles exposed to to thermal cycles (sudden and slow cooling) were determined. When findings were evaluated, it was determined that for both marbles, sudden cooling damaged more than slow cooling. However, after thermal cycles, it was determined that strength loss in Hazar Verde Antico marble was higher than in Elazı̆ Rosso Levanto. Similarly, the increase in porosity and water absorption in Hazar Verde Antico marble is higher than Elazig Rosso Levanto.
\end{abstract}

Keywords: Elazığ rosso levanto, Hazar verde antico, Point load strength, Thermal cycle

\footnotetext{
${ }^{*}$ Ea Engin ÖZDEMIR; ozdemir.engin@inonu.edu.tr, Tel: (0422) 37747 32, orcid.org/ 000-0002-6043-0403
} 


\section{Giriş}

Alp-Himalaya kuşağında yer alan Türkiye, dünya tarihinin en eski doğal taş işletmeciliği yapan ülkelerden birisidir. Doğal taş üretimi ve ihracatı bakımından dünya sıralamasında ilk 10 ülke arasında yer alarak Türkiye'nin cari açığının kapanmasında önemli bir rol oynamaktadır (Uysal, 2018). Doğal taşlar hem fiziko-mekanik özellikleri hem de estetik görünümlerinden dolayı inşaat ve yap1 malzemesi olarak kullanımı her geçen gün artmaktadır. Son yıllarda, dış cephe kaplamacılığı, heykelcilik, dekorasyon, süs eşyalarının yapımı, mezarcılık vb. sektörler başta olmak üzere birçok alanda doğal taş kullanımı yaygın bir artış göstermiştir. Dış mekânlarda kullanılacak doğal taşlar belirlenirken dayanıklılık parametresi dikkate alınması gereken önemli bir konudur. Fakat, doğal taşlar için kullanım alanları belirlerken sadece fiziksel ve mekanik özelliklerin dikkate alınması ve çeşitli doğrudan veya dolaylı çevresel faktörlerin etkisinin (1slanma-kuruma, yüksek sıcaklık, donma-çözünme, tuz kristalleşmesi, asit yağmurları vb.) göz ard1 edilmesi yapıda zamanla çeşitli fiziksel ve kimyasal bozuşmalara neden olmaktadır (Chen vd., 2004; Cantisani, 2009; Türkmenoğlu vd., 2020). Doğal taşların bozuşma dereceleri, uğradığı kötü çevresel etki veya etkilere ek olarak bünyesinde var olan mikro ya da makro yapılı gözeneklere de bağlıdır. Kayaçların mühendislik özellikleri termal etkilerle değişmektedir. Bu etkiler, doğal çevresel koşullardan (nem, iklim vb.) kaynaklı olabildiği gibi insan kaynaklı olaylar (yangın, asit yağmurları vb.) sonucunda da gelişebilir. Koca vd., (2006), Mithatpaşa Teknik ve Anadolu Lisesinde (İzmirKonak) meydana gelen yangın sonrasinda, alt kattaki iki mermer sütunun yoğun isıya maruz kaldıkları için yangın sonrası yük taşıma kapasitelerindeki meydana gelen değişimin büyüklüğü deneysel olarak araştırmışlardır. Yangın sırasında doğrudan alevlerin çarptığ 1 mermer kolonların yüzeyindeki sıcaklığı, sağlam karot numuneleri kullanılarak gözeneklilik ve sıcaklık arasında ampirik olarak kurulmuş bir ilişki kullanılarak $500{ }^{\circ} \mathrm{C}$ civarında olduğunu tahmin etmişlerdir. Yapılan deneysel çalışmalar sonucunda, mermer kolonlarının \%23 dayanım kaybına rağmen hala önemli bir yük taşıma kapasitesine sahip olduğunu tespit etmişlerdir. Ersoy vd., (2021), yüksek gözenekli kalkerli kayaçların mühendislik davranışları logaritmik/üssel 1sınma oranları ve gerçek bir yangında olduğu gibi farklı maruz kalma süreleri dikkate alınarak değerlendirmişledir. Araştırmacılar, $400{ }^{\circ} \mathrm{C}$ sıcaklığına kadar yoğunluk ve ağırlık kaybı değerlerinde önemli bir değişiklik olmadığını, 400 ile $600{ }^{\circ} \mathrm{C}$ arasındaki sıcaklıklarda ağırlık kaybı değerleri artmaya başlarken, yoğunluk değerlerinde azalma olduğunu ve 600 ${ }^{\circ} C^{\prime} y e$ kadar her sicaklık seviyesinde P-dalgası hiz değerleri düştügünü belirtmişlerdir. Ayrıca, $600{ }^{\circ} \mathrm{C}$ sıcaklıktan sonra tüm bu özellikler önemli ölçüde değişirken en yüksek hasarın $800{ }^{\circ} \mathrm{C}$ 'den sonra olduğunu tayin etmişlerdir. Ersoy vd., (2021b), 200 ile $1000{ }^{\circ} \mathrm{C}$ arasındaki sıcaklıklara maruz birakılan killi kayaçlarda 1 sıl işlem ve maruz kalma süresinin, numunelerin mineralojik ve yapısal değişiklikleri ile fiziko-mekanik özellikleri arasındaki ilişkiyi deneysel olarak araştırmışlardır. Kayaçların tek eksenli basınç dayanımları 600 ${ }^{\circ} \mathrm{C}$ 'ye kadar artarken, artan sicaklık değerleri ile azalmaya başladığını belirlemişlerdir. $\mathrm{P}$ dalga hızının her sıcaklık artışına bağlı olarak azaldığını, birim hacim ağırlığının ise $600{ }^{\circ} \mathrm{C}$ 'ye kadar azalırken, artan sicaklık değerleri ile neredeyse sabit kaldığını tayin etmişlerdir. Genel olarak değerlendirildiğinde, insan ve çevresel kaynaklı etmenler kayacın gözenekliliğini artırırken buna bağlı olarak dayanımını ise azaltmaktadır. $\mathrm{Bu}$ nedenle, doğal taşların doğal veya insan kaynaklı çevresel faktörlerden nasıl etkilendiklerini anlamak yapının uzun ömürlü olması açısından oldukça önem arz etmektedir (Royer-Carfagni, 1999; Vazquez vd., 2012; Careddu ve Marras, 2013; Özgüven ve Özçelik, 2014).

Bazı araştırmacılar termal şok ve termal yaşlandırma uygulamasının doğal taşları nasıl etkilediklerini araştırmışlardır. Mutlutürk vd., (2004), 10 farklı kayaç kullanarak donma-çözünme ve termal şok döngüsü sayısına bağlı olarak kayaçların mekanik dayanımlarını tahmin etmek için bir bozunma fonksiyon modeli geliştirmişlerdir. Termal şok döngüsü için, kayaçları $100{ }^{\circ} \mathrm{C}$ 'de iki saat ssınma işlemine tabi tuttuktan sonra oda sicaklığında ani soğumaya bırakmıştır. Donma çözünme döngüsü için suda doygun hale getirdiği numuneleri $-20{ }^{\circ} \mathrm{C}$ 'de iki saat donma işlemine tabi tuttuktan sonra oda sıcaklığındaki suyun içine bırakmıştır. Sousa vd., (2005), farklı petrografik ve fiziksel özelliklere sahip dokuz granitinin fiziko-mekanik özellikleri ve dayanıklılığ üzerinde gözeneklilik ve fisürasyonun etkisini araştırmışlardır. Bu amaçla, laboratuvar koşullarında termal şok ve tuz kristalleşmesi deneyleri yaparak kayaçların petrografik ve fiziko-mekanik özelliklerinde meydana gelen değişimleri incelemişlerdir. Deneysel çalışmalar sonucunda, tuz kristalleşmesi döngülerinden ziyade termal şok döngülerinin etkin porozite değerini daha fazla arttırdığını, benzer olarak P dalga hızındaki düşmenin porozite ile ilişkili olduğunu vurgulamışlardır. Yavuz vd., 
(2006), 12 farklı karbonat kökenli kayaçların 20 döngü sonrası donma-çözülme ve termal şok etkisinden kaynaklanan fiziksel ayrışmaya bağlı fiziko-mekanik özelliklerindeki değişiminin belirlenmesinde kullanılacak bir model geliştirmeyi hedeflemişlerdir. Bu amaçla, doğal koşullarda, donma-çözülme ve termal şok sonrasında kayaçların P-dalga hızı, tek eksenli basınç dayanımı ve Schmidt sertliği değerlerini belirlemişlerdir. Termal şok döngüleri için sıcaklık değerini $100{ }^{\circ} \mathrm{C}$ 'de 18 saat seçerken, donmaçözülme için $-20 \quad{ }^{\circ} \mathrm{C}^{\prime} \mathrm{de} \quad 2$ saat olarak belirlemişlerdir. Araştırmacılar, döngü sayıları arttıkça kayaçların P-dalga hızı, tek eksenli basınç dayanımı ve Schmidt sertliği değerlerinde düşmeler olduğunu tespit etmişler ve bu üç girdi parametresine bağlı olarak çoklu regresyon modeli geliştirmişlerdir. Yavuz (2011), termal şok ve donma çözünme olaylarının andezitin fiziksel ve mekanik özelliklerine etkisini incelemiştir. Donma çözülme döngüsünde numuneleri $-20^{\circ} \mathrm{C}$ 'de 6 saat dondurduktan sonra oda sıcaklığındaki suda 18 saat bekletirken, termal şok döngüsünde $105^{\circ} \mathrm{C}$ 'de 18 saat etüvde 1 sinma işleminden sonra oda sıcaklığındaki suya 6 saat birakılarak bir döngü işlemini gerçekleştirmiştir. Her bir döngü için 5'er adet numune kullanılarak her 10 döngünün sonunda fiziko-mekanik testler gerçekleştirmiştir. 50 döngü sonunda ise deneysel çalışmayı sonlandırmıştır. Termal şok ve donma çözünme olaylarının döngü sayılarındaki artışa bağlı olarak, andezitin P-dalga hızı, Schmidt çekici sertliği ve basınç dayanımında düşüşlere, gözeneklilik ve su emme değerlerinde ise artışa neden olduğu tayin etmiştir. Akbay vd., (2012), 6 farklı doğal taş kullanarak donma çözünme ve termal şok döngü sayısına bağlı olarak numunelerdeki kütle kaybı ve parlaklık değerlerindeki değişimleri incelemişlerdir. Araştırmacılar, iki test grubu için 200x100x20 mm ebatlarına sahip plaka numuneler kullanmıştır. Donma çözünme döngülerinde, doygun hale getirilen numuneler $-20{ }^{\circ} \mathrm{C}$ 'de 6 saat dondurulduktan sonra oda sicaklığındaki saf suda 18 saat bekletmişlerdir. Termal şok döngülerinde ise $105{ }^{\circ} \mathrm{C}$ 'de 18 saat bekletildikten sonra oda sıcaklığındaki suya daldırılarak 6 saat bekletilmiştir. Her iki test için her 5 döngüde bir ölçüm alınmış ve 40 döngü sonunda deneysel çalışma sonlandırılmıştır. Donma çözülme döngülerine bağlı ağırlık kaybı daha fazla iken, yüzey parlaklığ fazla olduğunu belirlemişlerdir. Sarıcı ve Özdemir (2017), Doğu Anadolu Bölgesinde üretilen 6 farklı doğal taşın termal şok ve termal yaşlandırma uygulamasının numunelerin pürüzlülük ve renk değişimleri üzerine etkisini araştırmışlardır. $\mathrm{Bu}$ amaçla, $105{ }^{\circ} \mathrm{C}$ 'de 18 saat etüvde 1 sınmaya bırakılan numunelerin yarısı oda koşullarında havada diğer yarısı ise oda koşullarında su içerisine bırakılarak ani sıcaklık değişimine maruz bırakmışlardır. Deneysel çalışmalar sonucunda her iki termal işlem sonucunda, numunelerin pürüzlülük ve renk değişimlerinde önemli bir etki bırakmadıklarını tayin etmişlerdir.

$\mathrm{Bu}$ çalışmada, Elazığ Vişne ve Petrol Yeşili mermerlerinin termal döngüler sonrası fiziksel ve mekanik özelliklerinde meydana gelen değişimler araştırılmıştır. $\mathrm{Bu}$ amaçla, $20 \mathrm{kez}$ ani ve yavaş gelişen 1sı değişimlere maruz bırakıldıktan sonra kütle kaybı, ağırlıkça-hacimce su emme ve nokta yükleme dayanım indeks değerlerindeki değişimler belirlenerek yorumlanmıştır.

\section{Materyal ve metot}

\subsection{Malzeme}

Deneysel çalışmada, Elazığ-Alacakaya ilçesi Altıoluk köyü civarında bulunan Elazı̆g Vişne (Rosso Levanto) ve Petrol Yeşili (Verde Antico) mermerleri kullanılmıştır. Şekil 1'de, örneklerin alındığı lokasyona ait yer bulduru haritası, Şekil 2'de ise sahalara ait görüntüler verilmiştir.



Şekil 1. Yer bulduru haritası (Demiroğlu, 2018) 




Şekil 2. Örnek alınan sahaların görünümü; a) Elazığ vişne mermer ocağı b) Petrol yeşili mermer ocağı

Her iki ocak birbirlerine oldukça yakın olup ocaklar arası mesafe yaklaşı $1.5-2.0 \mathrm{~km}$ civarındadır. Kullanılan örneklerin temel fizikomekanik özellikleri tayin etmek için 50x50x50 mm ebatlarına sahip her bir mermer için 5 adet numune kullanılmıştır. Numunelerin birim hacim ağırlıkları TS EN 1936, Mohs sertlik değerleri TS 6809 ve tek eksenli basınç dayanımları ise TS EN 1926 standardına göre gerçekleştirilmiştir. Bu fiziksel ve mekanik özellikleri TS standartlarına göre belirlenmiş ve Tablo 1'de sunulmuştur. Termal döngüler için ise her bir mermer türünden 30'ar adet $3 \times 4 \times 4 \mathrm{~cm}$ ebatlarına sahip olmak üzere toplam 60 numune derlenmiş̧ir. Ayrıca X-Işsını Floresans (XRF) sonuçları Tablo 2'de verilmiştir.

Tablo 1. Örneklerin bazı fiziksel-mekanik özellikleri

\begin{tabular}{|c|c|c|c|c|c|c|}
\hline & \multicolumn{3}{|c|}{ Elazığ vişne mermeri } & \multicolumn{3}{|c|}{ Petrol yeşili mermeri } \\
\hline & Min. & Max. & Ort. & Min. & Max. & Ort. \\
\hline $\begin{array}{l}\text { Doğal birim hacim } \\
\text { ağırlığ }\left(\mathrm{kN} / \mathrm{m}^{3}\right)\end{array}$ & 26.55 & 26.62 & 26.58 & 25.67 & 25.74 & 25.70 \\
\hline $\begin{array}{l}\text { Doygun birim hacim } \\
\text { ağırlığ } 1\left(\mathrm{kN} / \mathrm{m}^{3}\right)\end{array}$ & 26.63 & 26.70 & 26.66 & 25.77 & 25.83 & 25.80 \\
\hline $\begin{array}{l}\text { Kuru birim hacim } \\
\text { ağırlığ } 1\left(\mathrm{kN} / \mathrm{m}^{3}\right)\end{array}$ & 26.44 & 26.53 & 26.48 & 25.58 & 25.65 & 25.61 \\
\hline Mohs sertliği & 4 & 4 & 4 & 4 & 4 & 4 \\
\hline $\begin{array}{l}\text { Tek eksenli basınç } \\
\text { dayanımı }(\mathrm{MPa})\end{array}$ & 87.2 & 101.2 & 94.5 & 74.9 & 90.3 & 82.2 \\
\hline
\end{tabular}

Tablo 2. Numunelerin XRF analizi sonuçları

\begin{tabular}{lll}
\hline & Elazı̆̆ vişne mermeri (\%) & Petrol yeşili mermeri (\%) \\
\hline $\mathrm{SiO}_{2}$ & 23.18 & 25.60 \\
$\mathrm{Fe}_{2} \mathrm{O}_{3}$ & 7.34 & 8.62 \\
$\mathrm{CaO}$ & 20.71 & 18.7 \\
$\mathrm{MgO}$ & 26.25 & 25.4 \\
$\mathrm{Na} 2$ & $<0.014$ & 0.05 \\
$\mathrm{~K}_{2} \mathrm{O}$ & $<0.0012$ & - \\
$\mathrm{Al}_{2} \mathrm{O}_{3}$ & 1.328 & 0.26 \\
$\mathrm{P}_{2} \mathrm{O}_{5}$ & 0.361 & 0.07 \\
$\mathrm{ZnO}$ & 0.004 & 0.01 \\
$\mathrm{SrO}$ & 0.012 & 0.06 \\
$\mathrm{Co}$ & 0.022 & 0.01 \\
$\mathrm{~K}_{2} \mathrm{O}_{3}$ & 20.30 & 20.30 \\
\hline
\end{tabular}




\subsection{Termal işlemler}

Aynı sicaklık değerinde $\left(105 \pm 5^{\circ} \mathrm{C}\right)$ 1sitılan fakat farklı soğuma şekline (havada yavaş soğuma ve suda ani soğuma) maruz birakılan mermerlerin fiziko-mekanik özelliklerinde (ağıllı kaybı, ağırlıkça-hacimce su emme ve nokta yükleme dayanımı) meydana gelen değişimleri belirleyebilmek için laboratuvar ortamında termal döngüler oluşturulmuştur. Alacakaya Mermer A.Ş fabrikası tarafindan temin edilen $3 \times 40 \times 60 \mathrm{~cm}$ plakalar, nokta yükleme dayanımı test numunesi $(3 \times 4 \times 4 \mathrm{~cm})$ hazırlama işlemlerinde taş kesme testeresi kullanılarak her bir kaya türünden 30 'ar adet olmak üzere toplam 60 adet numune deney için hazırlanmıştır. Termal işlemlerin mermerlerin fiziko-mekanik özelliklerine etkisini belirlemek için numuneler üç guruba ayrıldı. Birinci grup numuneler herhangi bir termal işleme maruz bırakılmadan, ikincisi havada soğutularak ve son grup ise suda ani soğutularak deneysel işleme tabi bırakıldı. Ani suda soğuma işlemi için TS EN 14066'da belirtilen standart dikkate alınmıştır. Bu standarda göre numuneler $105 \pm 5^{\circ} \mathrm{C}^{\prime}$ lik etüvde 18 saat bekletildikten sonra oda sicaklığındaki saf su içerisine 6 saat süreyle bırakılarak termal döngü işlemine tutulmuştur. $\mathrm{Bu}$ işlem $20 \mathrm{kez}$ tekrarlandıktan sonra numunelerin ağırlık kayıpları (w), ağırlıkça su emme (Aw) ve hacimce su emme değerleri (Hw) değerleri tespit edilmiştir. Daha sonra dayanım deneyi olan nokta yükleme indeks değerleri tayin edilmiştir. Havada soğuma muamelesi için ise Lam dos Santos vd., 2011'de belirtilen yönteme göre yapılmıştır. Numuneler ilk olarak $105 \pm 5^{\circ} \mathrm{C}^{\prime}$ lik etüvde 18 saat bekletildikten sonra oda sicaklığına alınarak 6 saat süreyle soğumaya birakılmıştır. 20 döngü sonunda öncelikli olarak yıkıcı olmayan testler (ağırlık kaybı, ağırlıkça ve hacimce su emme) belirlendikten sonra nokta yükleme dayanımı değerleri tespit edilmiştir. Deneysel çalışmada kullanılan numuneler ve ekipmanlar Şekil 3'de verilmiştir.



Şekil 3. a) Deney numuneleri, b) Nokta yükleme test cihazı, c) Etüv, d) Termal işlemler

\subsection{Fiziksel ve mekanik testler}

Termal döngülere başlamadan önce kuru ağırlık, ağırlıkça ve hacimse su emme değerleri belirlenmiştir. Daha sonra termal döngülere tabii tutulmuştur. Döngüler tamamlandıktan sonra, mermerlerin termal işlem sonrası ağırlık kayıplarını tayin etmek $105 \pm 5^{\circ} \mathrm{C}^{\prime}$ lik etüvde 24 saat süre kurutularak son kütle değerleri tespit edilmiştir. Başlangıçtaki ağırlık ile döngülerin 
sonundaki ağırlık değerleri arasındaki kayıp yüzdesel olarak hesaplanarak ağırlık kaybı olarak kaydedilmiştir. Termal işlemler sonunda ağırlık kayıpları Eşitlik 1'deki formül ile hesaplanmıştır.

$\mathrm{w}=\frac{\mathrm{ms}-\mathrm{mi}}{\mathrm{mi}} \times 100$

\section{Burada;}

w: Ağırlık kaybı (\%)

ms: Döngülerin sonundaki numunelerin kütlesi (gr) mi: Döngüler öncesindeki numunelerin kütlesi (gr)

Mermerlerin ağırlıkça ve hacimce su emme değerleri ise TS 699'da belirtilen standarda göre tayin edildi. $\mathrm{Bu}$ amaçla, termal işlemler tamamlandiktan sonra numunelerin kuru ve doygun ağırlıkları ve hacimleri tespit edildi. Termal işlemler sonunda mermerlerin ağırlıkça ve hacimce su emme değerleri Eşitlik 2-3'teki formül ile hesaplanmıştır.

$\mathrm{Aw}=\frac{\mathrm{md}-\mathrm{mk}}{\mathrm{mk}} \times 100$

$\mathrm{Hw}=\frac{\mathrm{md}-\mathrm{mk}}{\mathrm{V}} \times 100$

Burada;

Aw: Ağırlıkça su emme (\%)

Hw: Ağırlıkça su emme (\%)

md: Döngülerin sonundaki numunelerin doygun kütlesi (gr)

mk: Döngüler öncesindeki numunelerin kuru kütlesi (gr)

$\mathrm{V}: \operatorname{Hacim}\left(\mathrm{cm}^{3}\right)$

Mermerlerin nokta yükleme dayanım değerleri ISRM 2007'de belirtilen standarda göre göre gerçekleştirilmiştir. Bu amaçla, her bir muamele ve kaya türü için 10 adet numune nokta yükleme testine tabii tutulmuştur. Mermerlerin nokta yük dayanım değerleri Eşitlik 4-7'deki formüller yardımıyla hesaplanmıştır.

$\mathrm{Is}=\frac{\mathrm{F}}{\mathrm{De}^{2}}$

$\mathrm{De}^{2}=4 \mathrm{~A} / \pi$

$\mathrm{F}=(\mathrm{De} / 50)^{0.45}$

$\mathrm{Is}_{(50)}=$ FxIs

Burada;

Is: Düzeltilmemiş nokta yük dayanım indeksi (MPa)
De: Eşdeğer numune boyutu (mm)

A: konik başlıkların temas noktalarından geçen örneğe ait en küçük kesit alanı $\left(\mathrm{mm}^{2}\right)$

F: Düzeltme faktörü

Is $_{(50)}$ : Düzeltilmiş nokta yük dayanım indeksi (MPa)

\section{Bulgular ve tartışma}

Elazığ vişne ve petrol yeşili mermerlerinin termal döngüler sonrası ağırlık kayıpları (w), ağırlıkça su emme (Aw), hacimce su emme (Hw) ve nokta yükleme dayanımı $\left(\mathrm{Is}_{(50)}\right)$ değerleri Tablo 3 'te verilmiştir. Tablo 3 . incelendiğinde termal döngüler sonrası Elazığ vişnenin petrol yeşili mermerine nazaran daha dayanıklı olduğu tespit edilmiştir. Herhangi bir döngüsel işleme tabii bırakılmamış nokta yükleme dayanım değerleriyle kıyaslandığında, Elazı ̆ vişne mermeri havada soğuma muamelesi sonrasında \%9.18 iken petrol yeşili mermeri \%15.59, suda ani soğuma muamelesi sonrasında Elazı̆̆ vişne mermeri $\% 17.86$ ve petrol yeşili mermeri \%27.32 dayanım düşüşü belirlenmiştir. Mermerlerin ağırlık kaybı, ağırlıkça ve hacimce su emme değerleri incelendiğinde ise Hazar petrol yeşili mermerindeki artış Elazığ vişne mermerine nazaran daha fazla olduğu görülmüştür. Tablo 3 . genel olarak incelendiğinde, ağıllık kayıpları, ağırlıkça-hacimce su emme değerleri artıkça nokta yükleme dayanım değerlerinde düşüşler söz konusudur. Bunun ana nedeni ise, termal işlemler sonucunda mermerlerin bünyesinde bulunan mikro yapılı çatlak veya gözeneklerin makro boyuta ulaşması veya yeni mikro ya da makro çatlakların meydana gelmesinden kaynaklı olduğu düşünülmektedir. $\mathrm{Bu}$ varsayımın nedeni ise porozite ve su emme değerlerindeki artışa bağlı olduğu söylenebilir.

\section{Tartışma ve sonuçlar}

Nokta yükleme dayanım deneyi, ucuz, pratik, taşınabilir, numune hazırlama kolaylığı hem laboratuvar hem de arazi koşullarında yapılabilir olması, kayaçların tek eksenli basma ve çekme dayanım değerlerini dolaylı olarak tahmininde kullanılması avantajları nedeniyle oldukça tercih edilen bir testtir. Bu çalışma Elazığ bölgesine ait iki farklı mermerin termal döngüler sonrası ağırlık kaybı, ağırlıkça su emme, hacimce su emme ve nokta yükleme dayanım değerlerinde meydana gelen değişimler araştırılmıştır. Deneysel ve istatistiksel çalışmalar sonucunda aşağıdaki bulgular elde edilmiştir. 
Tablo 3. Termal işlemler sonrası numunelerin fiziko-mekanik özellikleri

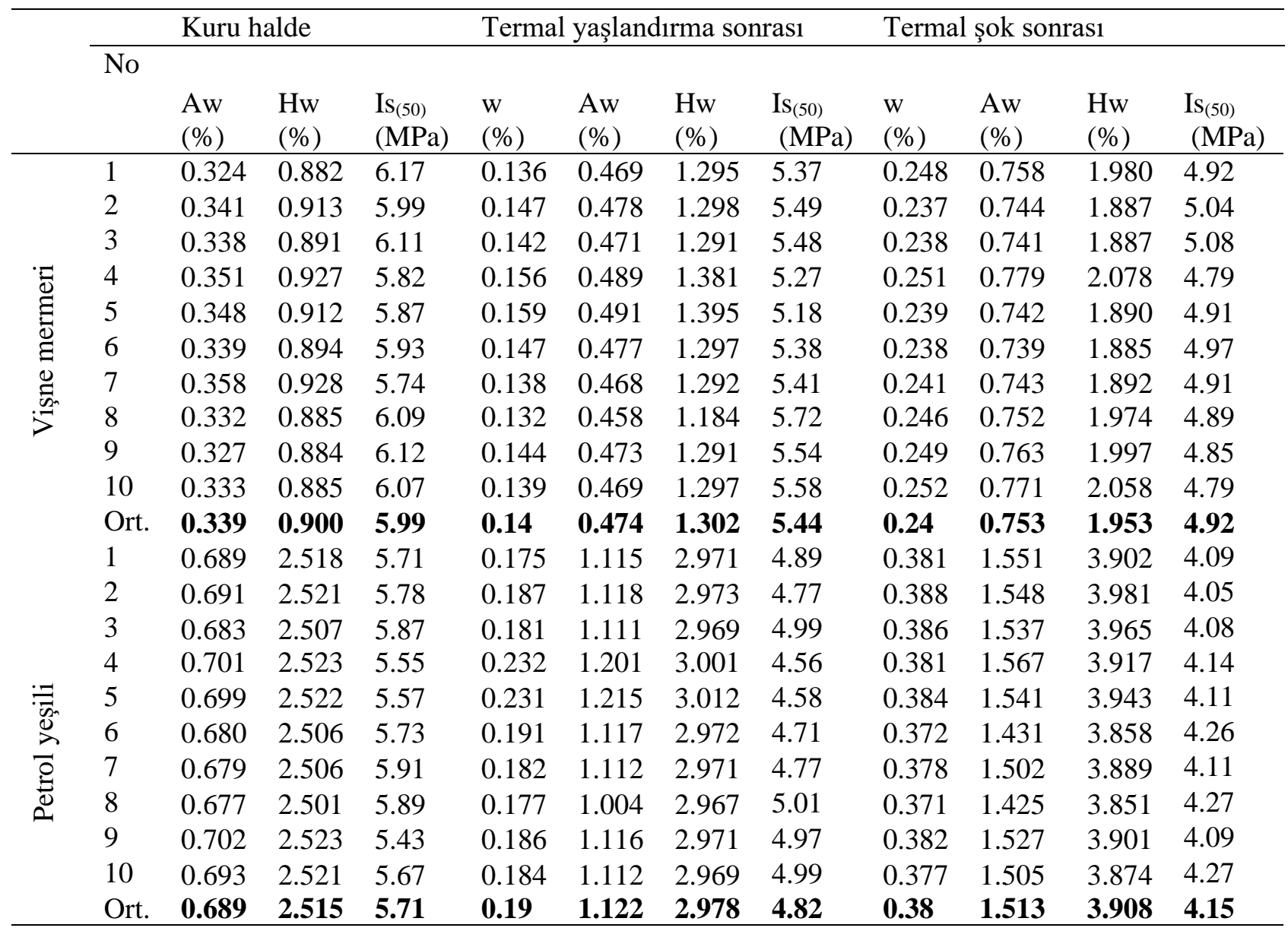

- Termal 1sinma ve farklı soğuma (havada ve suda) döngülerine maruz kalan her iki mermer için dayanım kayıpları gözlemlenmiştir. Fakat suda ani şok ile soğuyan numuneler, havada soğumaya birakılanlara nazaran daha fazla tahribata uğramışlardır.

- Fiziko-mekanik özelliklerindeki değişimler kıyaslandığında, Elazı̆ vişne mermerinin termal işlemler sonrasında petrol yeşili mermerine nazaran daha dayanıklı olduğu tespit edilmiştir. Petrol yeşili mermerinin termal döngüler sonrasında dayanım kaybının daha fazla olmasinın nedeni porozite ve su emme değerlerindeki artışa bağlı olduğu düşünülmektedir.

- Başlangıçtaki nokta yükleme dayanımı değeri baz alındığında, Elazı̆̆ vişne mermerinin havada soğuma döngüleri sonrasında $\% 9.18$, Hazar petrol yeşili mermerinin ise \%15.59 dayanım kaybı söz konusudur.

- Ani soğuma döngüleri sonrasında Elazığ vişne mermeri başlangıç nokta yükleme dayanımı değerinin \%17.86'sını, Hazar petrol yeşili mermeri ise \%27.32'sini kaybetmiştir.

- Suda ani şok ile soğuyan numunelerin ağırlık kayb1, ağırlıça ve hacimce su emme değerlerindeki artış havada soğuyanlara nazaran daha fazladır. Bu artışın Hazar petrol yeşili mermerinde daha fazla olduğu tespit edilmiştir.

$\mathrm{Bu}$ çalışmada elde edilen deneysel verilere dayanarak, her iki mermerinde özellikle suda ani şok ile soğuma döngüsüne maruz kalmayacak ortamlarda kullanılmasının daha uygun olduğu görülmektedir. Mermerler, 20 döngü sonunda \%17-27 arasında dayanım kaybı yaşamıştır. Döngü sayısındaki artışa bağlı olarak bu kaybın miktarında artış kaçınılmaz olacaktır. Böylesi termal döngülere maruz kalınabilecek ortamlarda kullanılan mermerlerin dayanım testlerine ek olarak termal etkileri içeren dayanım kaybı değerlerinin bilinmesinde fayda vardır. Aksi takdirde, beklenen ömründen ziyade daha erken zamanda yıpranmalar meydana gelir ve yenileme çalışmaları yapılması halinde ek maliyet oluşturabileceği anlamına gelmektedir. 


\section{Kaynaklar}

Akbay, D., Efe, T., Şengün, N. ve Demirdağ, S. (2012). Donma-çözülme ve termal şok koşullarının bazı mermerler üzerindeki etkilerinin incelenmesi. MERSEM'2012 Uluslararast 8. Mermer ve Doğaltaş Kongresi (ss.215-226). Afyon.

Cantisani, E., Pecchioni, E., Fratini, F., Garzonio, C.A., Malesani, P. ve Molli, G. (2009). Thermal stress in the Apuan marbles: Relationship between microstructure and petrophysical characteristics. International Journal of Rock Mechanics and Mining Sciences, 46, 128-137. https://doi.org/10.1016/j.ijrmms.2008.06.005

Careddu, N. ve Marras, G. (2013). The effects of solar UV radiation on the gloss values of polished stone surfaces. Construction and Building Materials, $\quad 49, \quad 828-834$. https://doi.org/10.1016/j.conbuildmat.2013.09.0 10

Chen, T.C., Yeung, M.R. ve Mori, N. (2004). Effect of water saturation on deterioration of welded tuff due to freeze-thaw action. Cold Regions Science and Technology, 38, 127-36. https://doi.org/10.1016/j.coldregions.2003.10.00 1

Demiroğlu, İ. (2018). Alacakaya ilçesi (Elazığ) ve yakın çevresinin yeralt k kaynakları ve bunların kullanım durumu. Yüksek Lisans Tezi, Fırat Üniversitesi Fen Bilimleri Enstitüsü, Elazı ̆̆.

Ersoy, H., Atalar, C., Sünnetci, M.O., Kolaylı, H., Karahan, M. ve Ersoy, A.F. (2021). Assessment of damage on geo-mechanical and microstructural properties of weak calcareous rocks exposed to fires using thermal treatment coefficient. Engineering Geology, 284(2021), 106046.

https://doi.org/10.1016/j.enggeo.2021.106046

Ersoy, H., Karahan, M., Kolaylı, H. ve Sünnetci, M.O. (2021b). Influence of mineralogical and microstructural changes on the physical and strength properties of post-thermal-treatment clayey rocks. Rock Mechanics And Rock Engineering, 54, 679-694. https://doi.org/10.1007/s00603$020-02282-1$

Koca, M.Y., Ozden, G., Yavuz, A.B., Kincal, C., Onargan, T. ve Kucuk, K. (2006). Changes in the engineering properties of marble in fire-exposed columns. International Journal of Rock Mechanics and Mining Sciences, 43, 520-530. https://doi.org/10.1016/j.ijrmms.2005.09.007

Lam dos Santos, J.P., Rosa, L.G. ve Amaral P.M. (2011). Temperature effects on mechanical behavior of engineered Stones. Construction and Building Materials, 25, 171-174. https://doi.org/10.1016/j.conbuildmat.2010.06.0 42

Mutlutürk, M., Altindag, R. ve Türk, G. (2004). A decay function model for the integrity loss of rock when subjected to recurrent cycles of freezing-thawing and heating-cooling. International Journal of Rock Mechanics and Mining Sciences, 41, 237$244 . \quad$ https://doi.org/10.1016/S13651609(03)00095-9.

Özgüven, A. ve Özcelik. Y. (2014). Effects of high temperature on physico-mechanical properties of Turkish natural building stones. Engineering Geology, 83, 127-136. https://doi.org/10.1016/j.enggeo.2014.10.006

Royer-Carfagni, G.F. (1999). On the thermal degradation of marble. International Journal of Rock Mechanics and Mining Sciences, 36, 119126.

Sarıcı, D.E. ve Özdemir E. (2017). Determination of effects of thermal changes on color and surface roughness at marbles. Bulletin of the Earth Sciences Application and Research Centre of Hacettepe University, 38(1), 57-70.

Sousa, L.M.O., Suarez del Rio, L.M., Calleja, L., Ruiz de Argondona, V.G. ve Rey, A.R. (2005). Influence of microfractures and porosity on the physico-mechanical properties and weathering of ornamental granites. Engineering Geology, 77, 153-168.

https://doi.org/10.1016/j.enggeo.2004.10.001

TS 6809. (2012). Mohs sertlik cetveline göre sertlik tayini. TSE. Ankara.

TS 699. (2009). Tabii yap taşlart-muayene ve deney metotları. TSE. Ankara.

TS EN 14066. (2004). Doğal taşlar-deney metotları termal şok etkisiyle yipranmaya direncin tayini. TSE. Ankara.

TS EN 1926. (2007). Doğal Taşlar-Deney MetotlartBasınç Dayanımı Tayini. TSE. Ankara.

TS EN 1936. (2010). Doğal taşlar-deney metotlar gerçek yoğunluk, görünür yoğunluk toplam ve açık gözeneklilik tayini. TSE. Ankara.

Türkmenoğlu Z. F., Özvan A., Erdeve Özvan E., Türkmenoğlu M., Akkaya İ., Varol O. O., Tapan M. ve Kahraman E. (2020). Yüksek Sicaklığın Doğal Taşların Petrografik, Parlaklık ve Pürüzlülük Özelliklerine Etkisi. Çukurova Üniversitesi Mühendislik Mimarlı Fakültesi Dergisi. 35(4), 937-947. https://doi.org/10.21605/cukurovaummfd.86878 5 
Uysal, M. (2018). The use of waste maroon marble powder and rronoxide pigment in the production of coloured self-compacting concrete. Advances in Civil Engineering. 2018, 1-10 https://doi.org/10.1155/2018/8093576

Vázquez, P., Luque, A., Alonso, F.J. ve Carlota M.G. (2012). Surface changes on crystalline stones due to salt crystallisation. Environ Earth Science, 69, 1237-1248. https://doi.org/10.1007/s12665-0122003-6

Yavuz, H. (2011). Effect of freeze-thaw and thermal shock weathering on the physical and mechanical properties of an andesite stone. Bulletin of Engineering Geology and the Environment, 70, 187-192. https://doi.org/10.1007/s10064-0100302-2

Yavuz, H., Altindag, R., Sarac, S., Ugur, I. ve Sengun, N. (2006). Estimating the index properties of deteriorated carbonate rocks due to freeze-thaw and thermal shock weathering. International Journal of Rock Mechanics and Mining Sciences, 43 , $767-775$. https://doi.org/10.1016/j.ijrmms.2005.12.004 